\title{
EVALUACIÓN ORGANOLÉPTICA DE OVAS DE 'PEZ VOLADOR' (Exocoetus volitans)
}

Ricardo Carranza La Torre ${ }^{1}$

\author{
R E S U M E N
}

El articulo presenta una iabla para evaluación sensorial del 'pez volador' (Exocoetus volitans) y a través de este caso particular, describe también los pasos comunes que se siguen para todo estudio de deterioro de productos marinos.

La tabla inchuye 5 atributos de igual importancia en términos de su influencia sobre la calidad del producto fresco.

\section{A B S T R A C T}

The article presents a Table for sensory assessment of roe of 'flying fish' (Exocoetus volitans) and through this particular case, describes also the common steps that are followed for every study of spoiling of seaproducts.

The table includes 5 attributes with alike importance in terms of their influence on quality of the fresh product.

\section{I.INTRODUCCIÓN}

La evaluación organoléptica de ovas de 'pez volador', un producto muy apreciado en el Japón y otros países del sudeste asiático, puede verse facilitada con el uso de una tabla organoléptica preparada para ese fin. Este producto se constituye, aunque estacionalmente, en un importante rubro de exportación para la zona sur del Perú.

Es en el área de Lomas (Arequipa) que se empięzan a colectar las ovas a partir de noviembre y hasta marzo o abril, utilizándose esteras sobre las que los peces 'vuelan' y 'caen', depositando las ovas que luego son ensacadas con sal y transportadas a los diversos centros de procesamiento localizados en algunas ciudades sureñas, entre ellas Tacna.

El procesamiento es sencillo pero laborioso. En forma resumida, consiste en remover las ovas de la 'fibra' gonadal (tejidos epitelial, conectivo y adiposo)

1. Ingeniero pesquero. por frotamiento contra mallas de abertura suficiente para permitir la separación de las ovas esféricas, lavar las mismas en recipientes con agitación y agua clara, que ayuden a la remoción de la fibra remanente, cuya presencia se nota como supernatante. Una vez limpias, las ovas se pesan y mezclan con un $10 \%$ en peso de sal pura (calidad extra y número de finura 1 ó 2), se colocan como granos individuales sueltos en bolsas de polietileno y éstas dentro de recipientes de hojalata, barnizados interiormente, debiendo completar un peso total aproximadamente de $18 \mathrm{~kg}$ y peso neto de 15 $\mathrm{kg}$, almacenándose finalmente a una temperatura de $-18^{\circ} \mathrm{C}$, según requerimiento de los importadores.

II. CONSIDERACIONES PRELIMINARES PARA LA ELABORACIÓN DE UNA TABLA
ORGANOLÉPTICA PARA OVAS DE 'PEZ
VOLADOR' (área de Tacna)

1. La materia prima se captura en Lomas y toma un promedio de 18 horas transportarlas hasta Tacna.

2. Para protegerla del deterioro en el tiempo que dura el viaje, se ensaca con sal, para deshidratarla. 
3. Por esta razón es necesario rehidratar la materia .prima antes de procesarla.

4. La rehidratación toma apenas unos cuantos segundos, cuando la materia prima es de calidad aceptable o buena.

5. Así, las condiciones físico-organolépticas y químicas (contenido de bases volátiles nitrogenadas o BVN) después de la rehidratación, deben corresponder al estado fresco original aproximadamente.

6. Los importadores reprocesan el producto de dos maneras: salado, tal como se exporta, y desalado, deshidratado, rehidratado, con añadido de saborizantes y otros.

\section{III.ELABORACIÓN DE LA TABLA}

La elaboración de una tabla de evaluación organoléptica implica siempre la observación del deterioro a través de aspectos o atributos reconocibles y correspondientes a grados de calidad asociados a puntajes fáciles de manejar por cualquier inspector. En el caso de ovas de 'pez volador', los atributos seleccionados para una prueba de deterioro fueron: textura / apariencia general, color, resistencia a la rotura por compresión, sabor y olor, todas con igual peso, en cuanto a su contribución a la calidad. La prueba de deterioro se hizo por triplicado, con producto recién llegado de Lomas y a la sombra, en enero de 1994. La tabla propuesta aparece más adelante.

\section{IV.TOMA DE MUESTRAS, EXAMEN Y ANÁLISIS}

Los métodos utilizados para muestreo, examen y análisis, deben ser métodos de aceptación internacional, como por ejemplo, los señalados para muestreo, y examen destructivo de alimentos preenvasados (CAC/RM 42 - 1969)/(NAC -6.5).

En el caso de ovas de 'pez volador' saladas y congeladas, el examen de las defectuosas involucra la determinación del contenido neto, para la cual se sugiere el siguiente procedimiento:

\section{DETERMINACIÓN DEL CONTENIDO NETO DE LAS OVAS DE 'PEZ VOLADOR' ENSALMUERADAS Y ALMACENADAS EN CONGELACIÓN}

1. Ábrase el envase que contiene las ovas ensalmueradas y congeladas, después de sacarlo de la cámara de almacenamiento y colóquese el contenido en una bolsa plástica y ésta en un recipiente con agua dulce a temperatura ambiente.
2. Luego de descongelado el contenido, colóquese en un tamiz de tela metálica, previamente tarado,

TABLA № 01: Para la evaluación organoléptica de ovas de 'pez volador'

\begin{tabular}{|c|c|c|c|}
\hline ATRIBUTO & DESCRIPCION & PUNTAJE & CALIDAD \\
\hline \multirow[t]{4}{*}{$\begin{array}{l}\text { TEXTURA } \\
\text { APARIENCIA } \\
\text { GENERAL }\end{array}$} & $\begin{array}{l}\text { Firme, elástica a presión entre } \\
\text { uñas de pulgares, turgente. } \\
\text { Apariencia atractiva, suelta. }\end{array}$ & 5 & A \\
\hline & $\begin{array}{l}\text { Todavia firme, ligeramente menos } \\
\text { elástica (más blanda), menos } \\
\text { turgente. Apariencia suelta. }\end{array}$ & 4 & B \\
\hline & $\begin{array}{l}\text { Firmeza disminuída notoriamente, } \\
\text { elasticidad muy disminuida (muy } \\
\text { blanda) turgencia débil. Apariencia } \\
\text { pegajosa con exudado. }\end{array}$ & 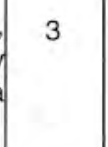 & $\mathrm{C}$ \\
\hline & $\begin{array}{l}\text { Firmeza vencida, sin elasticidad, } \\
\text { sin turgencia. Apariencia pegajosa, } \\
\text { agrumada, deshidratada. }\end{array}$ & 2 & D \\
\hline \multirow[t]{3}{*}{ COLOR } & $\begin{array}{l}\text { Naranja fuerte con brillo, contra } \\
\text { superficie blanca y bajo luz } \\
\text { natural. }\end{array}$ & 5 & A \\
\hline & $\begin{array}{l}\text { Naranja claro, con brillo. } \\
\text { Amarillo-blanquecino, opaco con } \\
\text { menos brillo. }\end{array}$ & $\begin{array}{l}4 \\
3\end{array}$ & $\begin{array}{l}\text { B } \\
\text { C }\end{array}$ \\
\hline & Naranja oscuro-rojizo. & 2 & $\mathrm{D}$ \\
\hline \multirow[t]{3}{*}{$\begin{array}{l}\text { RESISTENCIA } \\
\text { A ROTURA } \\
\text { POR } \\
\text { COMPRESIÓN }\end{array}$} & $\begin{array}{l}\text { Buena entre uñas de pulgar e } \\
\text { indice y entre incisivos, una vez } \\
\text { en posición, se aplica compresión } \\
\text { sin resbalamiento; revienta. }\end{array}$ & 5 & A \\
\hline & $\begin{array}{l}\text { Disminución de elasticidad } \\
\text { (aumento de blandura), dificulta } \\
\text { compresión y rotura; no revienta, } \\
\text { sólo se rompe. }\end{array}$ & 4 & B \\
\hline & $\begin{array}{l}\text { Compresión y rotura más difíciles, } \\
\text { hay resbalamiento, uñas se } \\
\text { juntan y no se rompe, necesario } \\
\text { cizallar (deslizar una uña sobre la } \\
\text { otra) para romper. }\end{array}$ & 3 & C \\
\hline \multirow[t]{5}{*}{ SABOR } & $\begin{array}{l}\text { No hay, se aplasta, es casi una } \\
\text { pasta. }\end{array}$ & 2 & $\mathrm{D}$ \\
\hline & $\begin{array}{l}\text { Salado mediano-ligero, no } \\
\text { desagradable, neutro. }\end{array}$ & 5 & A \\
\hline & Salado mediano-neutro. & 4 & B \\
\hline & $\begin{array}{l}\text { Salado mediano-fuerte, sensación } \\
\text { fi brosa. }\end{array}$ & 3 & C \\
\hline & $\begin{array}{l}\text { Salado, mediano-picante, irrita } \\
\text { mucosas. }\end{array}$ & 2 & D \\
\hline \multirow[t]{3}{*}{ OLOR } & A limpio, fresco, a mar. & 5 & A \\
\hline & A mar o pescado pero intenso. & 4 & B \\
\hline & $\begin{array}{l}\text { A mar muy intenso, a guardado. } \\
\text { Muy intenso a mar, a pescado } \\
\text { malogrado, muy abombado, } \\
\text { desagradable. }\end{array}$ & 3 & C \\
\hline
\end{tabular}


limpio y seco, con aberturas cuadradas de dimensiones menores que el tamaño de grano más pequeño.

3. Después que se ha drenado toda la salmuera, pésese el tamiz que contiene el producto, réstese el peso del tamiz a la cantidad resultante, agréguese el peso resultante de 4 .

4. Coléctese la salmuera en un recipiente de vidrio tarado y limpio, colóquese un salinómetro, léase la marca de flotación y réstese la cantidad de sal correspondiente. Luego, súmese la cantidad resultante al peso de 3 ; esta suma se considerará como el contenido neto del envase.

La aceptación de muestras implica todos los recipientes cuya calidad signifique defectos por debajo de las tolerancias establecidas, por ejemplo:

\section{BIBLIOGRAFÍA}

ZAITZEV, V. Fish Curing And Processing, Mir Publishers, Moscow 1969

KREUZER, R. Fish Inspection and Quality Control.

IEHO. A Guide to Fish and Fish Inspection, London 1980.

CARRANZA, R. Deterioro organoléptico y químico de tres
- Presencia de hongos - ninguna muestra.

- BVN 30 mg \% N - ninguna muestra

- Alteración del olor - $0 \%$ mediante recuento, etc.

La aceptación de un lote debe necesariamente significar que el número total de defectuosos no sea mayor que el número de aceptación del plan de muestreo correspondiente y que el contenido neto medio de todos los recipientes examinados no sea menor que el mínimo establecido.

Finalmente, es recomendable acompañar evaluaciones sensoriales, con mediciones objetivas de la calidad, en el caso de las ovas de 'pez volador', La determinación de BVN y su correlación con los grados de deterioro llenaría plenamente esta necesidad.

especies de pescado almacenados a temperaturas ambiente y refrigeración. Tesis Ing. Pesq. UNA La Molina, 1977. Lima - Perú.

BERTULLO, V. Tecnología de los productos y subproductos de pescados, moluscos y crustáceos. Hemisferio Sur, Bs As, 1975.

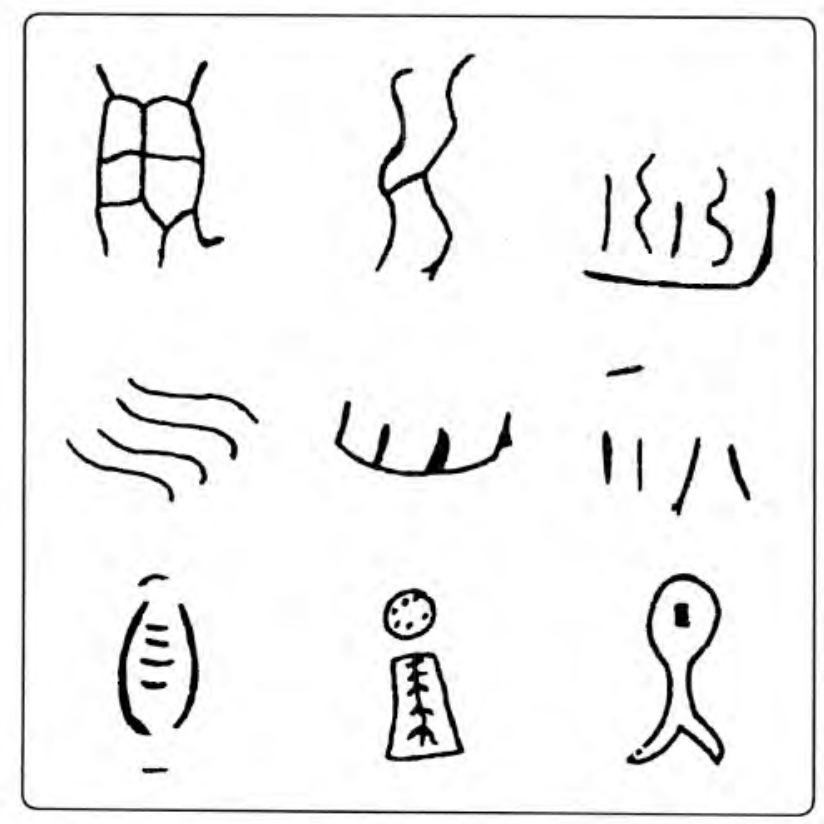

Signos compuestos con determinada funcionalidad, de carácter simbólico. 